\title{
Microstructural Features and Mechanical Properties after Industrial Scale ECAP of an Al-6060 Alloy
}

\author{
P. Frint ${ }^{\mathrm{a}}$, M. Hockauf, T. Halle, G. Strehl* ${ }^{*}$ T. Lampke and M.F.-X. Wagner \\ Chemnitz University of Technology, Institute of Materials Science and Engineering, \\ Erfenschlager Str. 73, 09125 Chemnitz, Germany \\ * S+C Extrusion Tooling Solutions GmbH, Kaiserau 2, 51789 Lindlar, Germany \\ aphilipp.frint@mb.tu-chemnitz.de
}

Keywords: equal-channel angular pressing (ECAP), scale-up, industrial scale, mechanical properties, ultrafine-grained (UFG), microstructure, aluminium alloy

\begin{abstract}
Future applications of ultrafine-grained, high performance materials produced by equalchannel angular pressing (ECAP) will most likely require processing on an industrial scale. There is a need for detailed microstructural and mechanical characterisation of large-scale, ECAP-processed billets. In the present study, we examine the microstructure and mechanical properties as a function of location and orientation within large $\left(50 \times 50 \times 300 \mathrm{~mm}^{3}\right)$ billets of an Al-6060 alloy produced by ECAP $\left(90^{\circ}\right.$ channel angle) with different magnitudes of backpressure. The internal deformation is analysed using a grid-line method on split billets. Hardness is recorded in longitudinal and crosssectional planes. In order to further characterise the local, post-ECAP mechanical properties, tensile tests in different layers are performed. Moreover, low-voltage scanning transmission electron microscopy observations highlight relevant microstructural features. We find that the homogeneity and anisotropy of mechanical properties within the billets depend significantly on the geometry of the shear zone. We demonstrate that deformation gradients can be reduced considerably by increasing the backpressure: The opening-angle of the fan-shaped shear zone is reduced from $\psi \approx 20^{\circ}$ to $\psi \approx 7^{\circ}$ when the backpressure is increased from 0 to $150 \mathrm{MPa}$. Backpressures of $150 \mathrm{MPa}$ result in excellent homogeneity, with a relative variation of tensile mechanical properties of less than $7 \%$. Our investigation demonstrates that ECAP is suitable for processing homogenous, high performance materials on a large scale, paving the way for advanced industrial applications.
\end{abstract}

\section{Introduction}

Manufacturing, characterisation and optimisation of ultrafine-grained bulk materials processed by ECAP has been of scientific interest for several years. Ultrafine-grained (UFG) materials typically exhibit average grain sizes in the range of $100 \mathrm{~nm}$ to $1 \mu \mathrm{m}$. Compared to their conventional, coarse-grained counterparts, these materials often exhibit a significantly increased strength [1-4]. The majority of previous investigations have been done on materials processed by ECAP in laboratory scale. Only a rather small number of investigations were focused on large-scale ECAP [5-8]. Considering the needs of future practical applications, there clearly is a need for scaling up the ECAP technique. Moreover, detailed microstructural and mechanical characterisation of largescale, ECAP-processed billets are required to broaden our understanding of size and scaling effects when scaling up from laboratory to industrial dimensions. In this paper, we report on the homogeneity of an UFG Al-6060 alloy processed by large-scale ECAP with different magnitudes of backpressure (BP). We examine the local microstructure and the corresponding mechanical properties, and we analyze the influence of shear zone geometry, which can be altered by applying different magnitudes of BP. 


\section{Materials and Experimental Procedure}

Extruded bars (square cross-section: $50 \times 50 \mathrm{~mm}^{2}$ ) of commercial purity Al-6060 (see Table 1) were solid-solution annealed at $525^{\circ} \mathrm{C}$ for 2 hours, followed by quenching in water. The annealed material exhibits a grain size in the range of 200 to $500 \mu \mathrm{m}$. The billets were then processed at room temperature in an ECAP-die with an internal angle of $\Phi=90^{\circ}$, resulting in an effective strain of approximately 1.1 [9]. The pressing speed was $20 \mathrm{~mm} \mathrm{~s}^{-1}$. Different billets were processed by one pass each, with BPs of $0,75,150$ or $200 \mathrm{MPa}$. To illustrate size, figure 1 shows a large-scale billet $\left(50 \times 50 \times 500 \mathrm{~mm}^{3}\right)$ processed by ECAP in the solution treated condition without BP.

Table 1: Chemical composition (wt.-\%) of the investigated Al-6060 alloy.

\begin{tabular}{|c|c|c|c|c|c|c|c|c|c|}
\hline & $\mathrm{Si}$ & $\mathrm{Fe}$ & $\mathrm{Cu}$ & $\mathrm{Mn}$ & $\mathrm{Mg}$ & $\mathrm{Zn}$ & $\mathrm{Ti}$ & $\mathrm{V}$ & $\mathrm{Al}$ \\
\hline $\mathrm{Al}-6060$ & 0.44 & 0.18 & 0.02 & 0.03 & 0.50 & 0.02 & 0.01 & 0.01 & bal. \\
\hline
\end{tabular}

In order to characterise the geometry of the shear zone as a function of the applied BP, a 'grid-line method' was used: Prior to ECAP, billets were cut lengthwise, and an equidistant laser grid (squares of $5 \times 5 \mathrm{~mm}^{2}$ ) was prepared on the interior surfaces (see also figures 3 and 4). Furthermore, hardness (HBW 62.5/2.5) was measured on the cross-sectional and longitudinal planes after ECAP to characterize the in-plane homogeneity of the post-ECAP deformation.

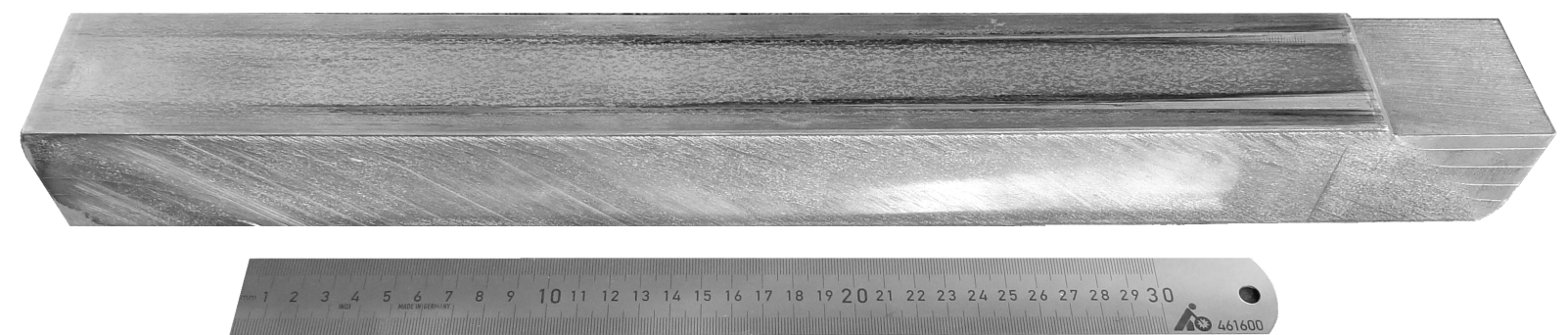

Fig. 1: ECAP-processed billet $\left(50 \times 50 \times 500 \mathrm{~mm}^{3}\right)$.

To investigate the local, post-ECAP mechanical properties, tensile tests were performed at room temperature with an initial strain rate of $10^{-3} \mathrm{~s}^{-1}$. Tensile specimens oriented in extrusion direction (x-direction, see figure 2) were taken from five different layers (i.e., different $\mathrm{z}$-values). After machining, the tensile specimens were subjected to an aging heat treatment at $170{ }^{\circ} \mathrm{C}$ for $20 \mathrm{~min}$ in order to achieve an optimised combination of strength and ductility, as reported in [10]. Finally, microstructural features of the as-pressed material were examined by optical microscopy and low-voltage scanning transmission electron microscopy analysis (STEM) in the longitudinal plane.

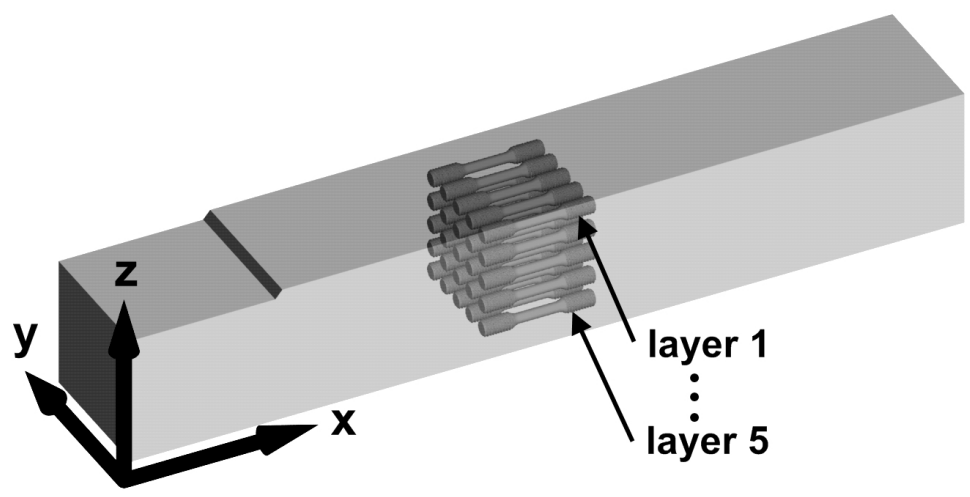

Fig. 2: Locations of tensile specimens and relevant directions used in this study. 


\section{Results and Discussion}

Figure 3 shows the deformed laser grid in the shear zone of a billet that was ECAP-processed without BP. The opening angle of the fan-shaped zone can be estimated by considering the first deviation from linearity (i.e., the onset of curvature) of both vertical and horizontal grid-lines. Using this method, an opening angle of $\Psi \approx 20^{\circ}$ was determined for a billet pressed without BP. With a $\mathrm{BP}$ of $150 \mathrm{MPa}$, this angle can be considerably reduced to $\Psi \approx 7^{\circ}$, figure 4 . In this case, the outer corner of the die was completely filled and no radius at the lower billet surface occurred. In figure 3, the deformation pattern of the grid lines that have already passed the shear zone exhibits some curvature from $0 \mathrm{~mm}$ to about $5 \mathrm{~mm}$ above the bottom. This indicates a reduced shear strain in the bottom region: If no BP is applied, the shear in the bottom part is superimposed with, or gradually replaced by, rotation around the y-axis. This leads to a decrease of the induced effective strain since the rotation does not contribute to the deformation. In contrast, perfectly sheared grid lines can be observed in the billet processed with a BP of $150 \mathrm{MPa}$. This is a strong indication of a more homogeneous, simple shear deformation.

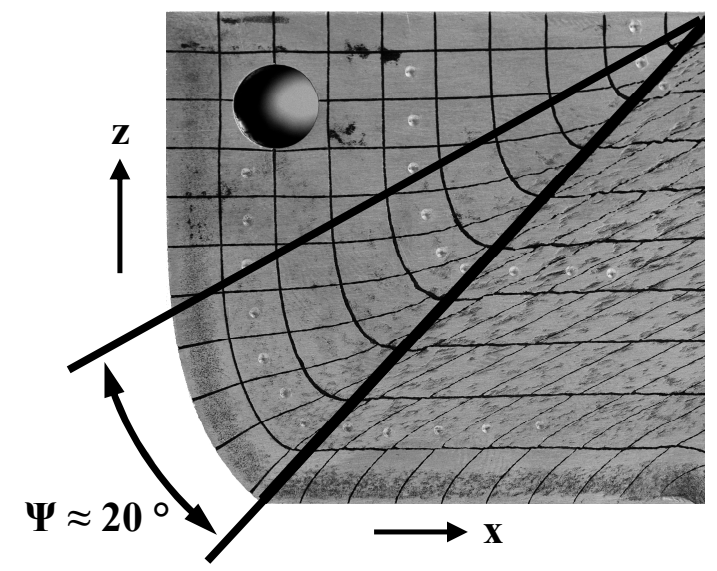

Fig. 3: Opening angle of fan-shaped shear zone after ECAP without BP.

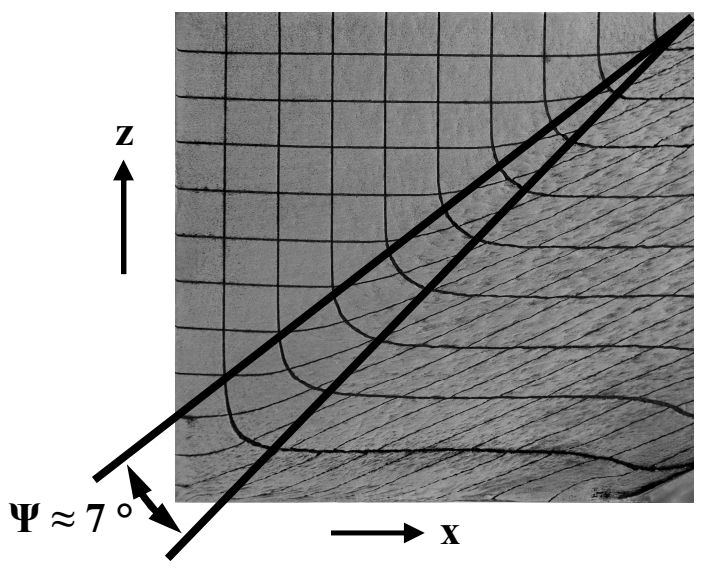

Fig. 4: Opening angle of fan-shaped shear zone after ECAP with a BP of $150 \mathrm{MPa}$.
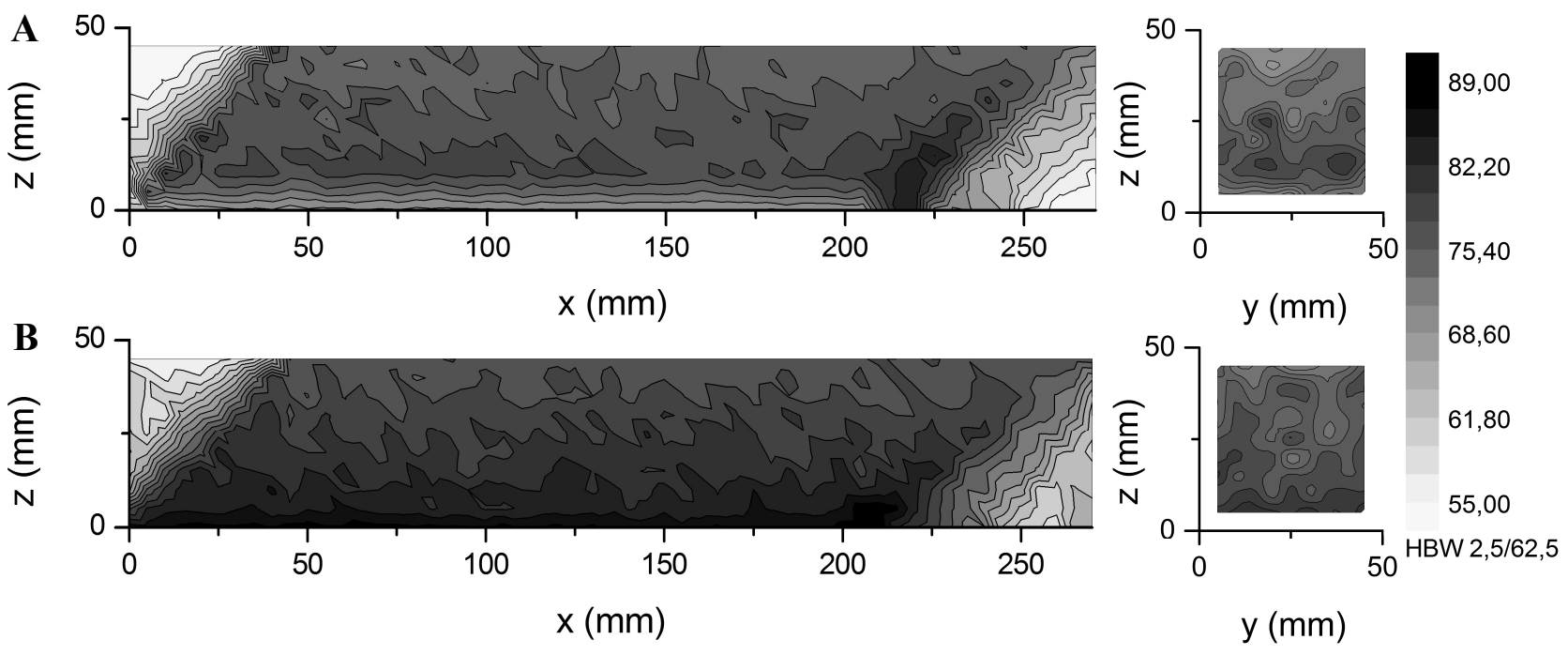

Fig. 5: Distribution of hardness in longitudinal and transversal planes. The billets were processed (A) without BP and (B) with a BP of $150 \mathrm{MPa}$.

Figure 5 shows the results of hardness measurements taken from the longitudinal and transversal planes of the Al-6060 alloy after one pass without and with (150 MPa) BP. Each longitudinal (transversal) plot was calculated from 550 (81) indents, with a spacing of $5 \mathrm{~mm}$. It is obvious that the applied BP also influences the hardness distribution. Processing without BP (figure 5 A) leads to 
a heterogeneous distribution of hardness from top to bottom of the billets. Hardness increases from the top of the billet to a region 10-15 mm above the bottom to a maximum of $80 \mathrm{HBW}$. Below this maximum, a local minimum $(70 \mathrm{HBW})$ is observed. It is likely that this minimum occurs due to the large opening angle of the shear zone, which results in a lower shear strain at the bottom of the billet. In contrast to the observed variations in z-direction, the lengthwise distribution is very homogeneous. The hardness along $\mathrm{x}$-direction is almost constant, with the exception of a rather localised maximum that occurs in regions deformed at the beginning of ECAP-processing (see figure $5 \mathrm{~A}$ at $\mathrm{x} \approx 220 \mathrm{~mm}$ ). Figure $5 \mathrm{~B}$ represents the hardness distribution in a billet processed with a $B P$ of $150 \mathrm{MPa}$. A local minimum at the bottom of the billet, as shown in figure $5 \mathrm{~A}$, disappears due to the applied BP. The same observation can be made for the localised maximum at the beginning of the billet. Only a slight increase of hardness from top to bottom within the billet remains, which shows a deviation of less than $10 \%$ (for comparison, commercially extruded materials exhibit deviations of about $10 \%$ ).

In order to evaluate the distribution (and a potential heterogeneity) of local mechanical properties, we now consider the results of tensile testing. Figure 6 summarizes the stress-(plastic) strain curves of the material in different layers (see figure 2) after ECAP-processing without BP. The $0.2 \%$ proof stress varies from $216 \mathrm{MPa}$ (layer 1) to $255 \mathrm{MPa}$ (layer 4), which is equivalent to a relative deviation of $\approx 18 \%$. The corresponding values of ultimate tensile strengths (UTS) vary in a similar range. Layers 1 and 2 exhibit the lowest, and layer 4 the highest, UTS, with a maximum difference of $29 \mathrm{MPa}$. Parameters describing ductility vary between the considered layers as well - the elongation at fracture and the uniform elongation (UE) differ by about $7 \%$ and $1.5 \%$, respectively. Figure 7 shows the stress-(plastic) strain curves of the material in the different layers after ECAP with a $\mathrm{BP}$ of $150 \mathrm{MPa}$. It is obvious that deviations between the mechanical behaviour of individual layers are significantly reduced. In this case, the $0.2 \%$ proof stresses of all layers are close to that of layer 4 in the billets processed without BP. The relative deviation of proof stresses as well as of UTSs within these layers is reduced to less than $7 \%$. Moreover almost no differences in terms of UE are observed.

The absolute deviations of UTS and UE as a function of the applied BP are compared in figure 8 (figure 8 includes additional, preliminary results for BPs of 75 and $200 \mathrm{MPa}$ ). These data clearly demonstrate that BP plays a key role in homogenizing the distribution of mechanical properties inside the billet.

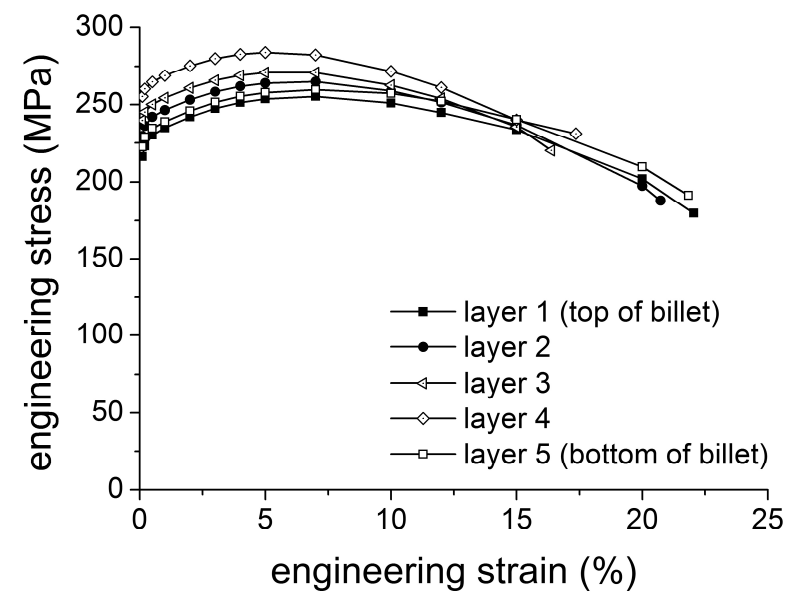

Fig. 6: Stress-(plastic) strain curves for the material after ECAP-processing with no BP in x-direction for different layers within the billet.

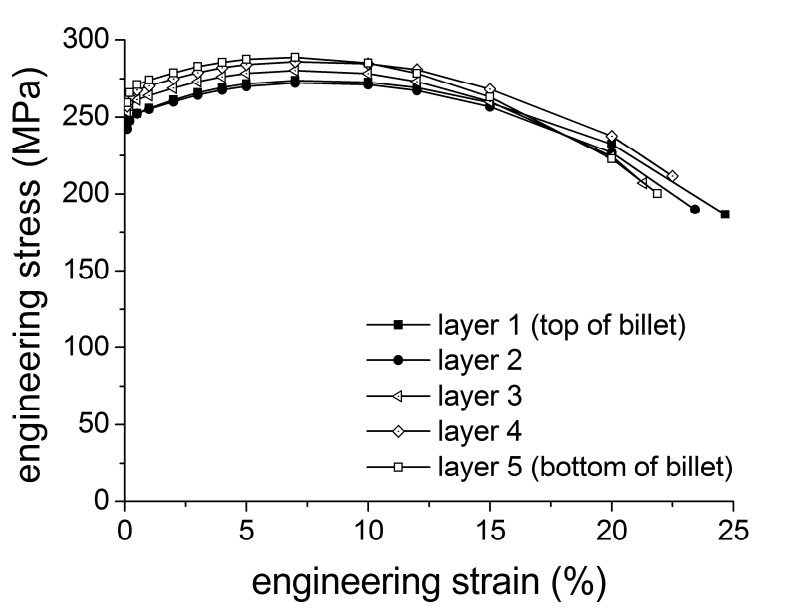

Fig. 7: Stress-(plastic) strain curves for the material after ECAP-processing with $\mathrm{BP}(150 \mathrm{MPa})$ in $\mathrm{x}$ direction for different layers within the billet. 


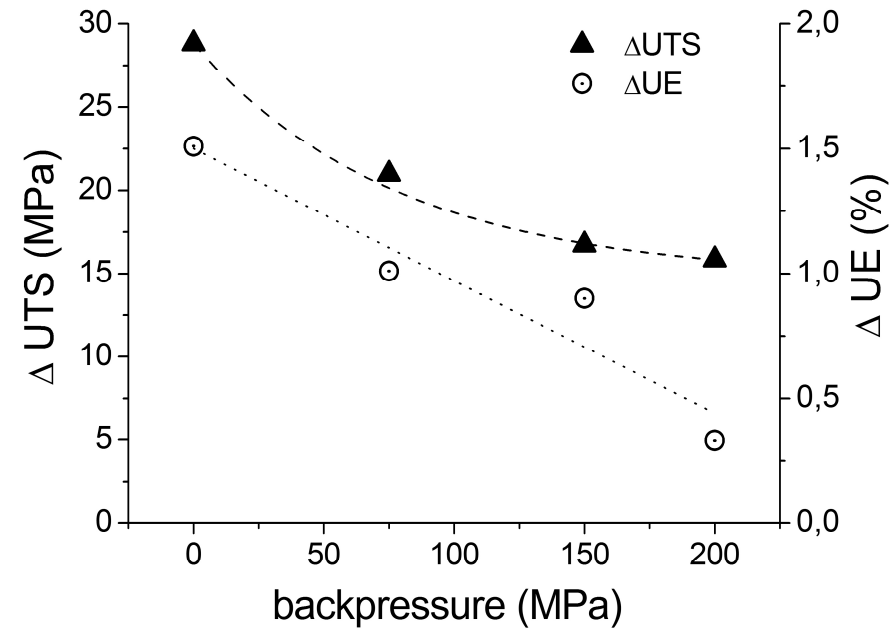

Fig. 8: Absolute deviations of UTS and UE in $x$-direction between different positions (layers) in the billet as a function of BP during ECAP.
Figures 9 and 10 show the microstructure in the longitudinal plane (x-z-plane, see also figure 2) of the ECAPed material, processed without $B P$ in layer 1 (lower tensile strength, figure 9) and layer 4 (high tensile strength, figure 10). The optical micrographs (figures $9 \mathrm{~A}$ and $10 \mathrm{~A}$ ) indicate the formation of micro-shear bands that are typical for simple shear deformation of aluminium. The STEM micrographs $(B, C)$ show a cell structure with a cell/subgrain-size less than $1 \mu \mathrm{m}$. Interestingly, despite the different mechanical properties, no distinct differences in terms of cell size or dislocation density between these two locations could be identified in our preliminary STEM analysis. We note that

$\mathrm{Xu}$ et al. [11] reported similar observations; they documented a somewhat higher area fraction of equiaxed grains in regions of higher hardness, and more elongated grains in low-hardness regions. They [11] argue that the grain shape tends to become more equiaxed when the imposed strain is sufficiently large. While there is a need for further STEM characterization to confirm the microstructural tendencies for a larger volume of the ECAPed material, our STEM results are in good agreement with the observations of $\mathrm{Xu}$ et al., and similar mechanisms may likely result in the differences in mechanical properties documented in figures 6 to 8. Finally, considering local maxima and minima in the hardness distributions of individual billets (in particular at no or low BP), further investigations (most importantly: X-ray analysis) are needed to take the evolution of textures at different locations into account.

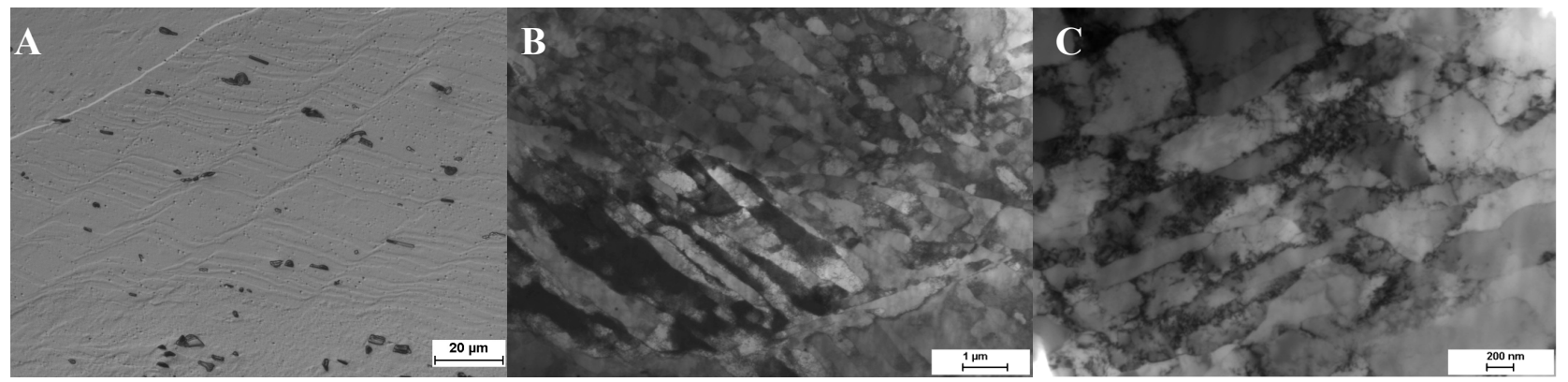

Fig. 9: Microstructure of the ECAP-material processed without BP in layer 1, analyzed by (A) optical microscopy, (B) and $(\mathrm{C})$ STEM.

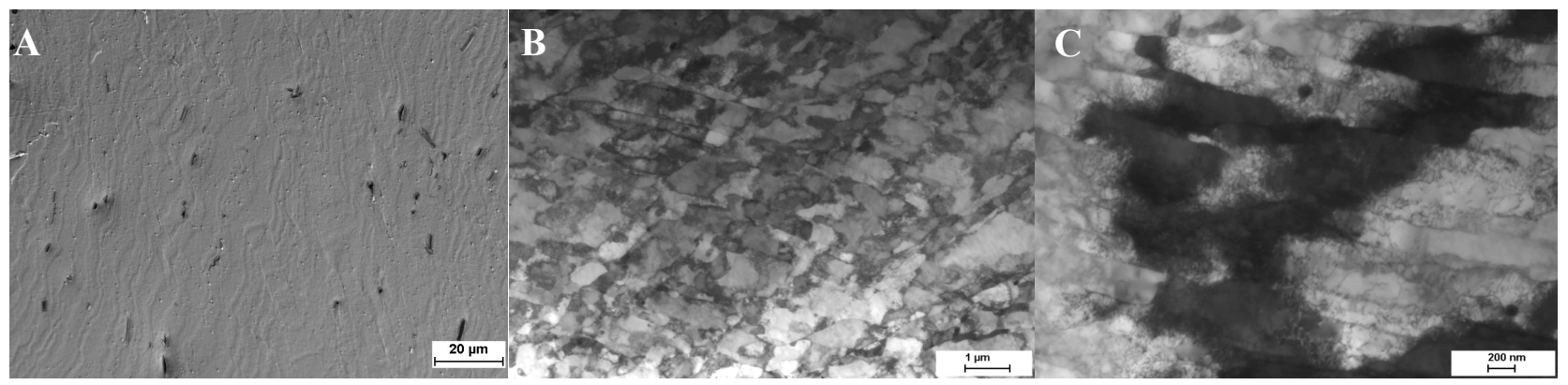

Fig. 10: Microstructure of the ECAP-material processed without BP in layer 4, as observed by (A) optical microscopy, (B) and (C) STEM. 


\section{Conclusions}

The process of equal-channel angular pressing was successfully scaled up to a large billet size of $50 \times 50 \times 500 \mathrm{~mm}^{3}$. This technique in principle enables the use of severely plastically deformed materials in structural applications and hence helps overcome one of the most persistent obstacles to a widespread use of ultrafine-grained materials. Our results are summarized as follows:

- The geometry of the shear zone was analysed using a grid-line method. An opening angle of $\Psi \approx 20^{\circ}$ was detected for the billet processed with no backpressure. With an increased backpressure of $150 \mathrm{MPa}$, this angle was considerably reduced to $\Psi \approx 7^{\circ}$.

- Hardness measurements were taken systematically in the cross-sectional and longitudinal planes. Differences in hardness distributions, depending on the applied backpressure, can be observed: Billets processed without backpressure exhibit a variation of hardness over the height of the billet, with a local minimum in the bottom region. Increasing backpressures lead to an increased homogeneity and reduces or even eliminates the local minimum.

- Tensile tests were performed in different layers. An inhomogeneous distribution of mechanical properties (relative deviations of about 18\%) was measured in a billet processed without backpressure. Backpressures of $150 \mathrm{MPa}$ result in excellent homogeneity, as expressed by a relative deviation of tensile mechanical properties of less than $7 \%$.

- Microstructural investigations of the ECAP-processed material reveal a cell/subgrain structure with an average size considerably less than $1 \mu \mathrm{m}$. However, the first microstructural results reported here (no essential difference in cell size and dislocation density) cannot fully account for the variation of mechanical properties; further investigations, including texture analysis, will provide a more complete picture of microstructure-property relations after equal-channel angular pressing on a large scale.

\section{Acknowledgements}

The authors gratefully acknowledge funding by the German Research Foundation (Deutsche Forschungsgemeinschaft, DFG) within the framework of the Research Center SFB 692.

\section{References}

[1] R. Z. Valiev, T. G. Langdon: Prog. in Mater. Sci. Vol. 51 (2006), p. 881

[2] C. Xu, Z. Száraz, Z. Trojanová, P. Lukáč, T. G. Langdon: Mater. Sci. and Eng. A Vol. 497 (2008), p. 206

[3] Z. Horita, T. Fujinami, M. Nemoto, T. G. Langdon: Journal of Mater. Proc. Tech. Vol. 117 (2001), p. 288

[4] V. M. Segal, A. E. Reznikov, A. E. Drobyshevskiy, V. I. Kopylov: Russ. Metall. (1981), p. 7

[5] S. Ferrasse, V. M. Segal, F. Alford, J. Kardokus, S. Strothers: Mater. Sci. and Eng. A Vol. 493 (2008), p. 130

[6] R. Srinivasan, B. Cherukuri, P. K. Chaudhury: Mater. Sci. Forum Vol. 503-504 (2006), p. 371

[7] Z. Horita, T. Fujinami, T. G. Langdon: Mater. Sci. and Eng. A Vol. 318 (2001), p. 34

[8] P. Frint, T. Halle, M. F.-X. Wagner, M. Hockauf, T. Lampke: Materialwiss. u. Werkstofftechnik Vol. 41 (2010), p. 814

[9] Y. Iwahashi, J. T. Wang, Z. Horita, M. Nemoto, T. G. Langdon: Scri. Mater. Vol. 35 (1996), p. 143

[10]M. Hockauf, L. W. Meyer, B. Zillmann, M. Hietschold, S. Schulze, L. Krüger: Mater. Sci. and Eng. A Vol. 503 (2009), p. 167

[11] C. Xu, M. Furukawa, Z. Horita, T. G. Langdon: Mater. Sci. and Eng. A Vol. 398 (2005), p. 66 